\title{
Influence of the Adhesive on the Load-Carrying Capacity of Glued Laminated Timber Members in Fire
}

\author{
MICHAEL KLIPPEL, ANDREA FRANGI, and MARIO FONTANA \\ ETH Zurich \\ Institute of Structural Engineering \\ Wolfang-Pauli-Strasse 15 \\ 8093 Zurich, Switzerland
}

\begin{abstract}
Design models for timber structures in fire usually take into account the loss in cross-section due to charring and the temperature-dependent reduction in strength of timber. For bonded timber elements like glued laminated timber beams it is assumed that the adhesive used does not influence the resistance of structural timber beams significantly. To investigate the fire resistance of bonded timber elements a comprehensive research project is currently in progress at the Institute of Structural Engineering of ETH Zurich, Switzerland. The aim of this research project is the development of a simplified design model for the fire resistance of bonded structural timber elements taking into account the behavior at elevated temperature of the adhesive used.

This paper presents experimental analyses and results of first calculations performed on the influence of the adhesive on the load-carrying capacity of glued laminated timber members in fire. It is shown that the temperature-dependent material properties of the adhesive used in the bondline of glued laminated timber beams have small influence on the shear resistance. For the investigated timber beams failure occurs mainly due to exceeding the bending moment resistance. Because of the steep temperature gradient in timber beams during fire exposure the temperature in the inner region of the cross-section is rather low; hence the shear capacity in the bondline between the different lamellas is still sufficient. However, in case of finger jointed lamellas of glued laminated timber beams, the influence of adhesive used in the finger joints is more significant and has to be considered. Tensile tests at elevated temperatures on finger jointed specimens confirmed the significant influence of the adhesive used.
\end{abstract}

KEYWORDS: adhesive, fire resistance, glued laminated timber, FEM, modeling, structural response, structural design.

\section{NOMENCLATURE LISTING}

$\begin{array}{llll}f_{t} & \text { tension strength }\left(\mathrm{N} / \mathrm{mm}^{2}\right) & \text { Greek } & \\ f_{c} & \text { compressive strength }\left(\mathrm{N} / \mathrm{mm}^{2}\right) & \alpha_{c} & \text { coefficient of heat transfer }\left(\mathrm{W} / \mathrm{m}^{2} \cdot \mathrm{K}\right) \\ f_{v} & \text { shear strength }\left(\mathrm{N} / \mathrm{mm}^{2}\right) & \varepsilon_{\text {res }} & \text { resultant emissivity by radiation }(-) \\ E_{c} & \text { modulus of elasticity for compression }\left(\mathrm{N} / \mathrm{mm}^{2}\right) & \sigma & \text { normal stresses }\left(\mathrm{N} / \mathrm{mm}^{2}\right) \\ E_{t} & \text { modulus of elasticity for tension }\left(\mathrm{N} / \mathrm{mm}^{2}\right) & \tau & \text { shear stresses }\left(\mathrm{N} / \mathrm{mm}^{2}\right) \\ T & \text { temperature }\left({ }^{\circ} \mathrm{C}\right) & & \\ t & \text { time (min) } & & \end{array}$

\section{INTRODUCTION}

Resorcinol-formaldehyde (RF) and phenol-resorcinol-formaldehyde (PRF) adhesives have been used for decades for bonding structural timber components. These adhesives are characterized by their high strength, durability and moisture resistance. PRF resins are generally used as cold curing adhesives. In the last years, new adhesives have entered the market: melamine-urea-formaldehyde (MUF) adhesives due to lower costs and shorter hardening times, and one-component polyurethane (PUR) adhesives, which are formaldehyde-free, fast curing at ambient temperature and offering a wide range of application possibilities (no mixing).

Finger joints are commonly used to produce engineered wood products like glued laminated timber beams. A relative large literature on the structural behavior of finger joints at ambient temperature [1-8] is available, but there is little information about structural behavior at elevated temperature. Fire tests 
performed with glued laminated timber beams bonded with RF and PRF adhesives never led to concerns about failure of the adhesive [9-11]. Nyman [12] studied the influence of temperature and moisture on the strength of timber and bonded joints and found that the timber strength was more sensitive to an increase in temperature than the RF adhesive. A series of tensile tests aimed at the analysis of the temperature influence on the timber strength parallel-to-grain of finger jointed boards for glulam carried out by Nielsen and Olesen [13] confirmed the test results of Nyman for elevated temperatures (160 and $230{ }^{\circ} \mathrm{C}$ respectively). However, these tests showed that the tensile strength of unjointed boards was higher than tensile strength of finger joints tested at a temperature of $90{ }^{\circ} \mathrm{C}$. Källander and Lind [14] analyzed the strength properties of glued laminated beams before and after fire exposure. The results showed that the adhesive types tested (PUR, UF, PVA and EPI) had a small influence on the behavior of the beams during and after fire exposure. No difference in charring rate during fire and in shear strength after fire was observed. It should be noted that the beams were not loaded during fire and a large proportion of the gluelines were not exposed to elevated temperature. Recently, glued laminated timber beams with finger joints in the outer lamella on the fire-exposed tension side were tested by König et al. [15]. The finger joints were bonded with various structural PRF, MUF and PUR adhesives that fulfill current approval criteria for use in load-bearing timber components. The tests showed no substantial difference of bending resistance at ambient temperature. In the fire situation, however, beams with PUR and MUF adhesives in the finger joints exhibited bending resistances of only 70 to $80 \%$ of the bending resistance of the beams with PRF-bonded finger joints.

The results of a series of oven tests carried out by Frangi et al. [16] to study the shear behavior of different adhesives at elevated temperature demonstrated that the behavior of PUR adhesives strongly depends on the type of adhesive. More recently, further investigation on the influence of temperature on the shear strength of glued wood joints showed large differences in thermal resistance and fracture behavior between the adhesive systems tested [17]. The thermal behavior of one-component polyurethane systems can be greatly varied by modifying their chemical structure. One PUR adhesive tested showed excellent thermal stability. Test results based on one particular polyurethane adhesive are therefore not valid for other polyurethane adhesives.

In Europe, structural adhesives must comply with performance requirements given in EN 301 [18] and EN 15425 [19]. With regard to performance at elevated temperature, the highest temperature in the tests according to these standards is $70{ }^{\circ} \mathrm{C}$, being held over two weeks under constant loading of the specimens. Therefore, the current European standards provide little or no information nor do they give a classification for adhesives at elevated temperature appropriate for fire design. In North America, as an alternative to costly full-scale testing for each structural application, a new standard ASTM D 7247 [20] was published in 2006, prescribing a method performing oven tests with pre-heated specimens with lap-shear joints and applying acceptance criteria that include temperatures considerably above $200{ }^{\circ} \mathrm{C}$. However, no link between these tests and the performance in fire has been demonstrated [15].

A comprehensive research project on the fire resistance of bonded timber elements (e.g. glued laminated timber beams, cross-laminated timber panels) is currently in progress at the ETH Zurich. The aim of the research project is the development of simplified design models for the fire resistance of bonded structural timber elements taking into account the behavior at elevated temperature of the adhesive used. An extensive testing program is planned, as a basis for the structural fire resistance models. This paper presents results of first calculations performed and experimental analyses on the influence of the adhesive on the resistance of glued laminated timber members in fire. First, a calculation model on the influence of adhesive used in the bondlines and in finger joints of glued laminated timber is presented. Then, the results on finger joints are compared to tests at elevated temperatures and fire tests performed by König et al. [15].

\section{CALCULATION MODEL}

The influence of the adhesive on the resistance of glued laminated timber members exposed on ISO-fire on three sides was studied using a sequentially thermal and mechanical numerical model. The thermal numerical analysis was performed using two-dimensional finite element models implemented in Abaqus [21]. The temperature development and distribution in the cross-section was used as input for the mechanical analysis. The heat transfer to the member's surface was modeled using temperatureindependent constant values according to EN 1991-1-2 [22] for the resultant emissivity by radiation $\varepsilon_{\text {res }}=0.8$ and the coefficient of heat transfer by convection $\alpha_{c}=25 \mathrm{~W} /\left(\mathrm{m}^{2} \cdot \mathrm{K}\right)$. Density, thermal conductivity 
and specific heat capacity of wood and charcoal vary as a function of temperature. The moisture migration and the change of moisture, i.e. the evaporation of water at a temperature of about $100{ }^{\circ} \mathrm{C}$ was simplified and implemented into the FE-simulation as latent heat. Mass transfer of moisture into or out of the wood was neglected. In the FE-thermal analysis, charring of wood (i.e. reduction of cross-section) was taken into account by gradually changing the thermal properties of wood into those of charcoal with increasing temperature. For the FE-thermal analysis, an initial density of $450 \mathrm{~kg} / \mathrm{m}^{3}$ and an initial moisture content of $12 \%$ were considered. The temperature-dependent relationships for the density and specific heat of wood and charcoal were implemented according to EN 1995-1-2 [23]. Cracks in the charcoal increase the heat flux due to radiation and convection. Thus, the thermal conductivity values of the char layer used in FE-thermal analyses are 'effective' values rather than 'real' material properties in order to take into account the increased heat flux due to cracks above about $500{ }^{\circ} \mathrm{C}$ and the degradation of the char layer at about $1000{ }^{\circ} \mathrm{C}$ [24]. For the FE-thermal analysis, the temperature-dependent relationship for the thermal conductivity of wood and charcoal was assumed according to EN 1995-1-2. The material properties of wood and charcoal used for the FE-thermal analysis were verified with a series of fire tests [25] on spruce specimens exposed to ISO-fire only on one side. The specimens had a dimension of $225 \times 95 \mathrm{~mm}$ and moisture content of about $12 \%$. Temperatures were measured in a depth of $6,18,30,42$ and $54 \mathrm{~mm}$ from the surface exposed to fire. Figure 1a shows the comparison between fire tests and FE-results for the temperatures measured at different depths. Experimental and numerical results were in good agreement.

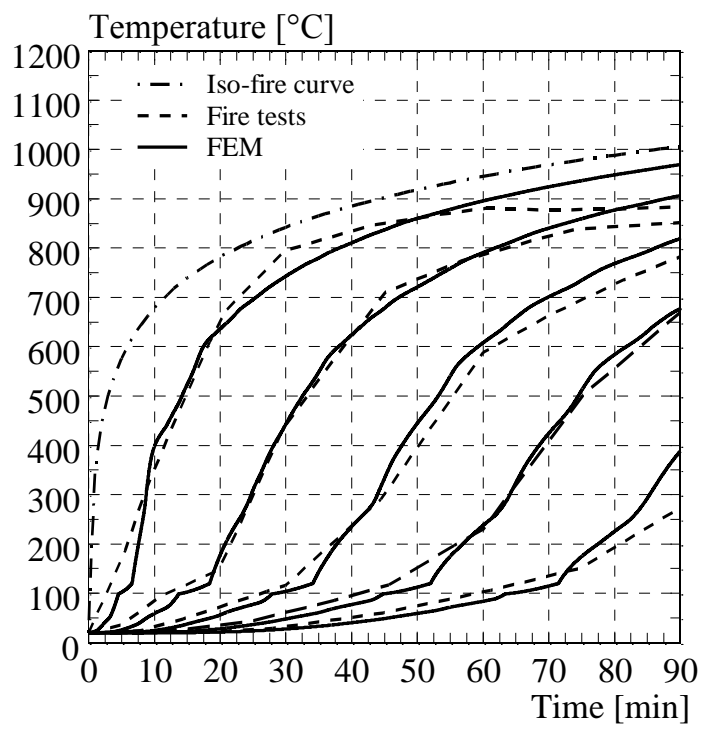

(a)

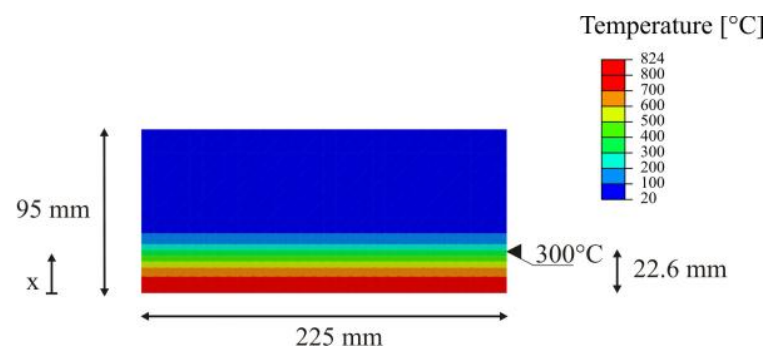

(b)

Fig. 1. (a) Comparison of measured [25] and calculated temperatures at different timber depths; (b) temperature distribution in the cross-section $(225 \times 95 \mathrm{~mm})$ after $30 \mathrm{~min}$ fire exposure.

For the mechanical analysis, the computer program CSTFire [26] based on a Visual Basic macro embedded in Excel was used. The temperature distribution in the cross-section calculated by the thermal finite element analysis and the relative strength and stiffness values given by EN 1995-1-2 were used as input parameters, i.e. compressive and tensile strengths $f_{c}$ and $f_{t}$, and the modulus of elasticity in compression and tension $E_{c}$ and $E_{t}$. These values are given as bi-linear functions of temperature from 20 to $300{ }^{\circ} \mathrm{C}$ with breakpoints at $100{ }^{\circ} \mathrm{C}$, also taking into account the effects of transient moisture situations and creep, see Fig. 2b. Regions with temperature higher than $300{ }^{\circ} \mathrm{C}$ were not considered as the strength of timber is assumed to decrease to zero for a temperature of $300{ }^{\circ} \mathrm{C}$. The software considers the possibility of permitting ductile behavior of wood at elevated temperatures. In contrast to ambient conditions where failure on the tension side of a beam is brittle, in the fire situation tensile failure of the outermost fibers won't cause immediate collapse of the member since a redistribution of internal stresses will take place as long as equilibrium is maintained. Since the reduction of strength and stiffness properties is different for tension and compression, CSTFire uses an iteration process, increasing the curvature of the member until the maximum moment resistance is reached. The element size used for the thermal and mechanical numerical analysis was chosen as $1 \mathrm{~mm} \times 1 \mathrm{~mm}$. 


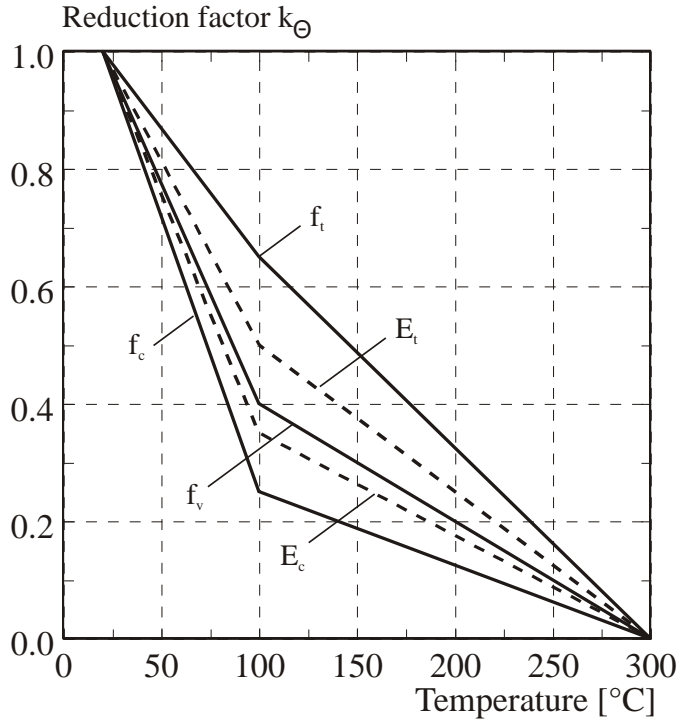

(a)

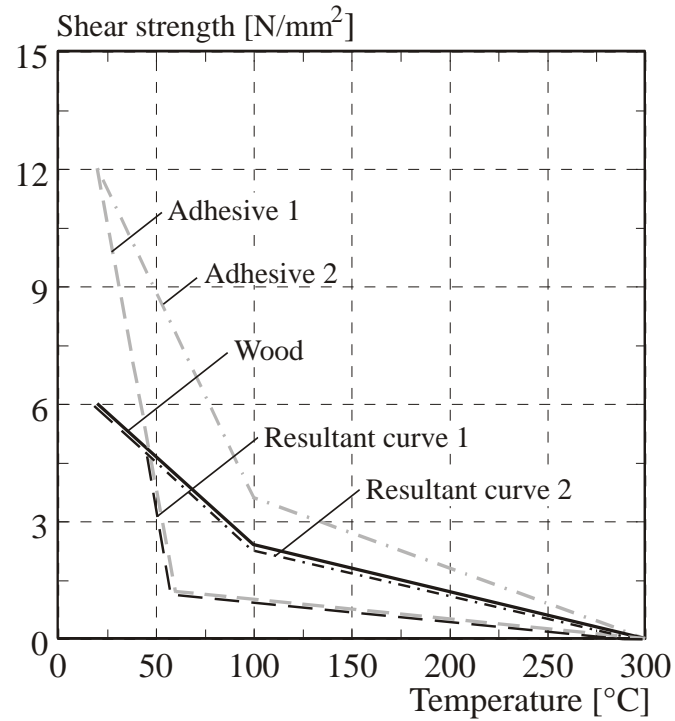

(b)

Fig. 2. (a) Reduction factors for strength and stiffness properties of wood according to EN 1995-1-2 [23];

(b) wood shear strength and different simplified approaches for the adhesive shear strength as function of temperature.

The cross-section's normal stress distribution was determined for ambient conditions $(t=0)$ and for different times of ISO-fire exposure. The normal stresses are considered as the stress distribution when bending failure occurs. As a next step the corresponding shear stress distribution in the cross-section can be calculated since the change in normal stress is directly related to the developed corresponding shear stress, see Fig. 3. In order to determine the magnitude and distribution of the shear stresses, a simple supported beam with a uniform distributed load was assumed. The maximum value of the shear stress at ambient temperature and under ISO-fire exposure can be found at the neutral axis. At ambient temperature the shear stress can be assumed to be constant over the width of the beam. In case of fire due to a temperature gradient in the cross-section the shear stress also varies in the width direction of the cross-section. The corresponding shear force can finally be calculated by integration of the resultant temperature-dependent shear stresses. The static equilibrium was calculated based on the hypothesis of Bernoulli. The calculated shear force can be stated as the maximum shear force in the cross-section when bending failure occurs.
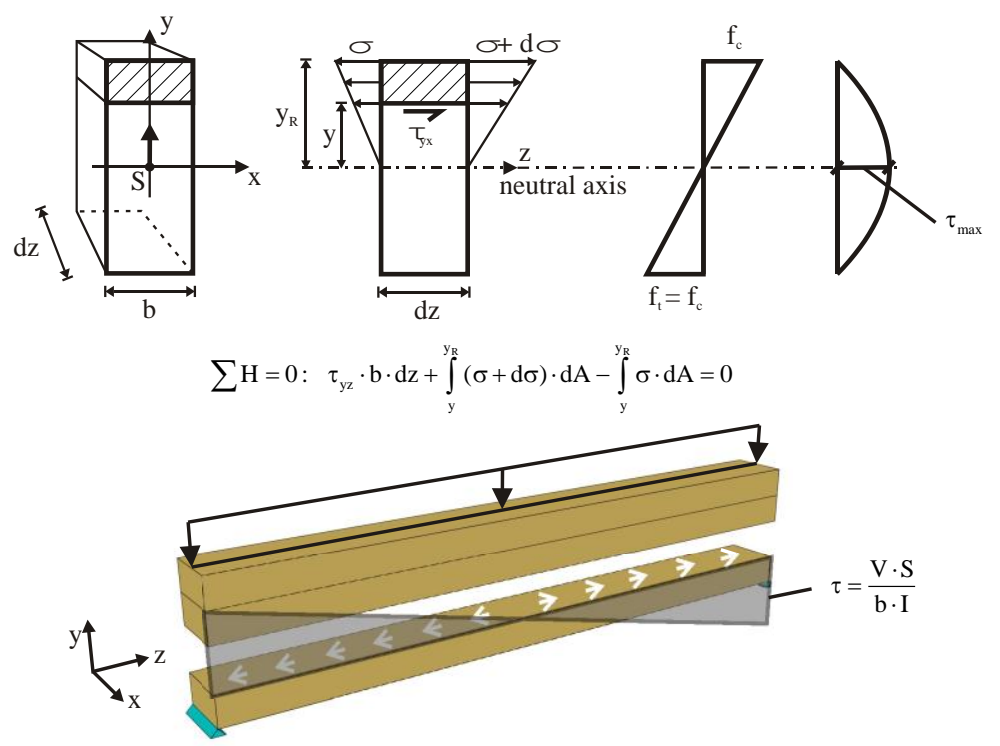

Fig. 3. Model for the calculation of the shear stress distribution in the cross-section of timber beams. 
The shear resistance in the bondline of glued laminated timber beams is calculated depending on the temperature distribution in the cross-section and the temperature-dependent material properties assumed for the timber and adhesive (Fig. 2b). The temperature-dependent reduction of the timber shear strength was assumed according to EN 1995-1-2, i.e. by a bi-linear function with a breakpoint at $100{ }^{\circ} \mathrm{C}$ (with $40 \%$ of the timber strength at ambient temperature). The decrease of adhesive shear strength with increasing temperature is not yet clearly understood. For the calculations performed the loss of strength of the adhesive the following two temperature-strength curves were studied:

- a bi-linear function with a breakpoint at $60{ }^{\circ} \mathrm{C}$ (with $10 \%$ of the adhesive strength at ambient temperature) representing an adhesive more sensitive to the influence of temperature (Fig. $2 \mathrm{~b}$, adhesive 1).

- a bi-linear function with a breakpoint at $100{ }^{\circ} \mathrm{C}$ (with $40 \%$ of the adhesive strength at ambient temperature) representing an adhesive less sensitive to the influence of temperature (Fig. 2b, adhesive 2).

The shear strength in the bondline is calculated by the minimum of the timber and adhesive strength dependent on the temperature (Fig. 2b). The material properties assumed for the adhesive 1 leads to the shear strength according to resultant curve 1, those of adhesive 2 to the shear strength according to resultant curve 2. During fire, a temperature gradient in the cross-section can be observed. For the resultant curve 1 especially at the outer regions with high temperatures the shear strength in the bondline is dominated by the strength of the adhesive whereas, in the inner regions of the cross-section with lower temperatures the shear strength is limited by the strength of the timber. The shear resistance in the bondline can finally be calculated by integration of the resultant temperature-dependent shear strength over the cross-section width.

\section{GLUED JOINTS}

The calculation model described in the above section was used to determine the influence of the adhesive strength between lamellas in glued laminated timber beams. For the analysis the height of the crosssections was taken as $200 \mathrm{~mm}$, while the width varied from 40 to $140 \mathrm{~mm}$. Small sections were selected because they are markedly influenced by elevated temperatures. The cross-sections were exposed to ISOfire on three sides with the top face being protected. It was assumed that the top face was adiabatic. Figure 4 gives for example the calculated temperature distribution of the cross-section of $100 \times 200 \mathrm{~mm}$ after $20 \mathrm{~min}$ ISO-fire exposure on 3 sides, assuming that the cross-section is initially unprotected from fire exposure. The corresponding maximum normal and shear stress distribution in the cross-section at bending failure is also shown in Fig. 4. Compressive and tensile strengths at ambient temperature used in the calculation model correspond to the values determined in Ref. [15] for the performed fire tests with glued laminated timber.
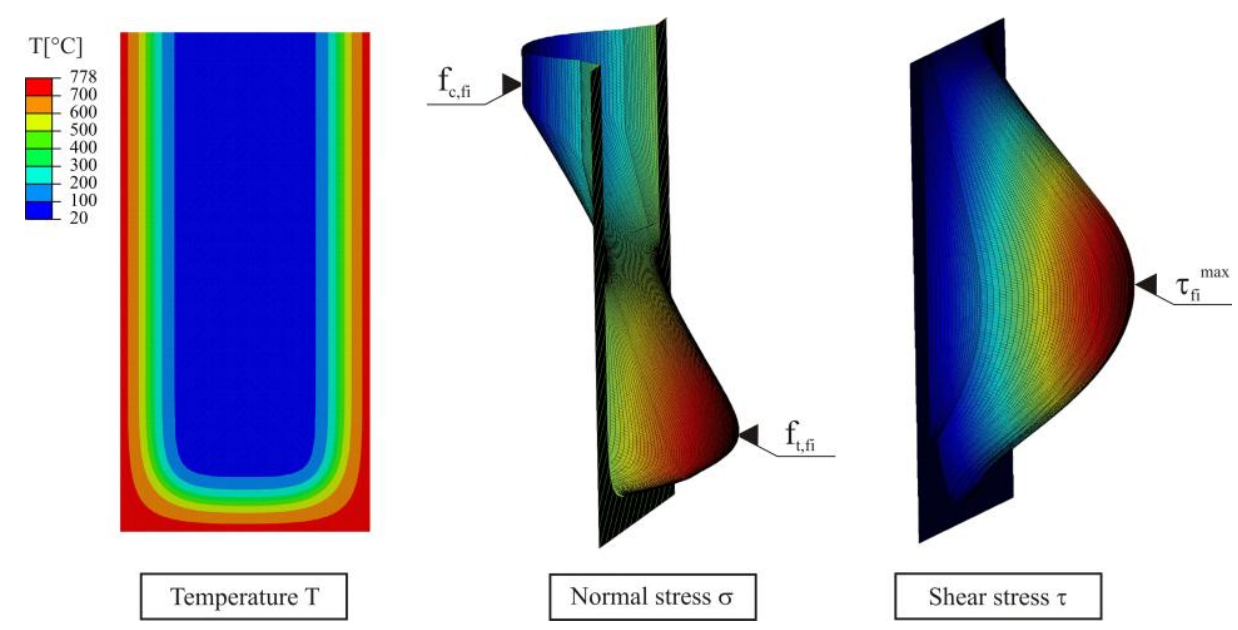

Fig. 4. Temperature distribution in the cross-section $(100 \times 200 \mathrm{~mm})$ after $20 \mathrm{~min}$ ISO-fire exposure and corresponding normal and shear stresses. 
In fire, due to the loss of strength and stiffness in the outer areas of the cross-section the shear stresses in the inner part of the section increase compared to ambient temperature. Furthermore, the neutral axis is shifted up in the cross-section with increasing time of fire exposure. The corresponding shear force at bending failure is calculated by integration of the resultant temperature-dependent shear stresses at the neutral axis.
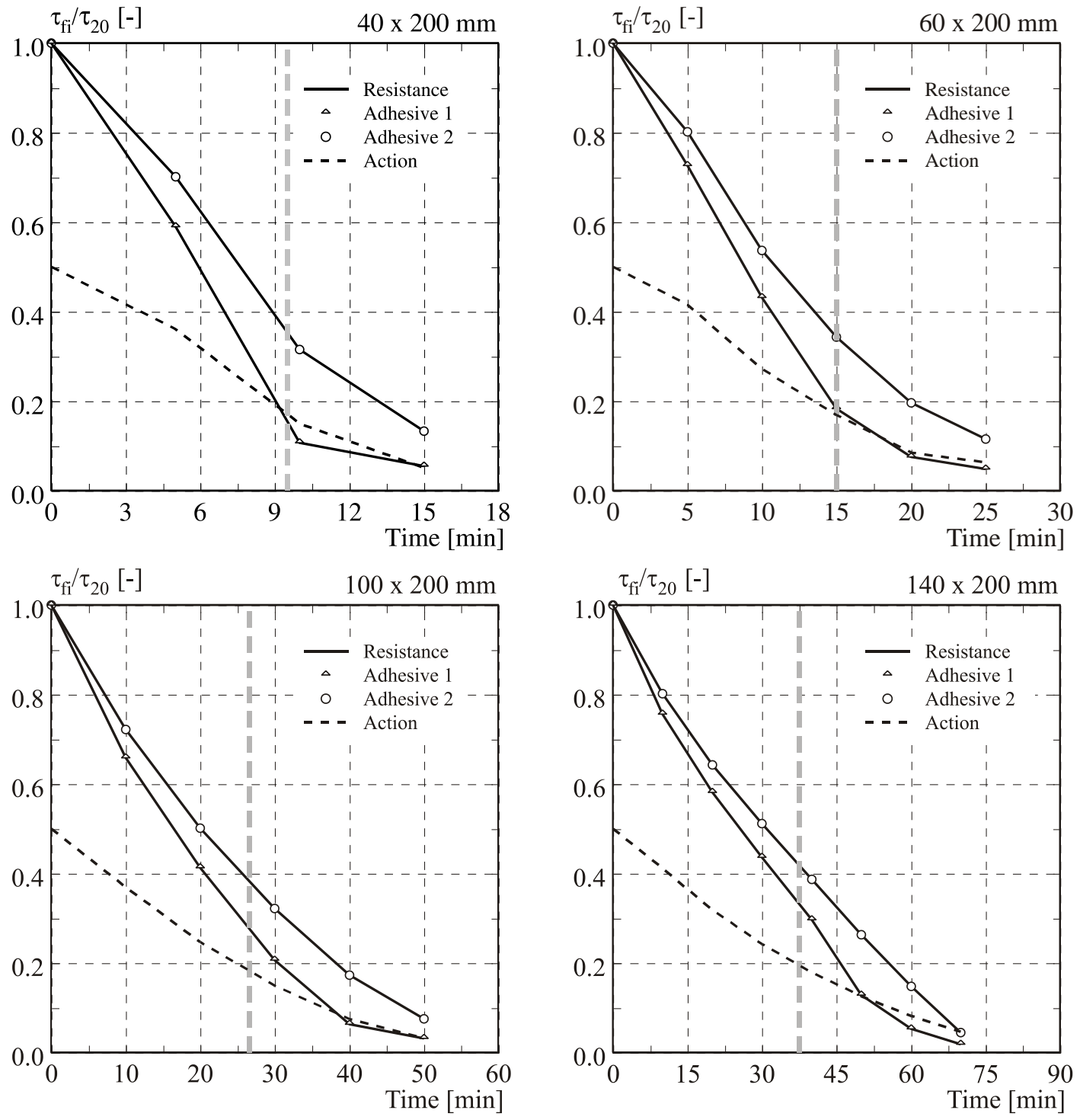

Fig. 5. Temperature-dependent reduction of shear resistance of glued laminated timber beams exposed to ISO-fire on 3 sides as a function of time for different cross-sections and type of adhesives (see Fig. 2). The vertical dashed grey line indicates the time of $30 \%$ relative bending resistance.

Figure 5 shows the calculated shear resistance of the bondline for the investigated cross-sections depending on the adhesive strength according to Fig. $2 \mathrm{~b}$. The vertical dashed grey lines indicate the time of $30 \%$ relative bending resistance determined by CSTFire, being a typical load ratio expected for fire design. Further, the black dashed lines ('action') show the shear stress to which the investigated beam is subjected to when bending failure occurs. It was assumed that at ambient temperature the shear stress reaches $50 \%$ of the shear resistance of the bondline. This high ratio was chosen in order to be on the safe side by the evaluation of the results. However, for common applications it is expected that the shear stress in the bondline at ambient temperature reaches much lower values than $50 \%$ of the shear resistance. With increasing width of the cross-section the influence of the adhesive on the shear resistance generally 
decreases. The reason is the steep temperature gradient in the cross-section leading to lower temperature in the inner part of the cross-section. Thus, also assuming adhesives that lose relative strength already at low temperature (adhesive 1 respectively resultant 1 , see Fig. $2 \mathrm{~b}$ ) the beam will fail because of bending failure.

A comparison of the shear resistance and the bending resistance shows that the shear resistance in the bondline for the investigated cross-sections is greater than the shear stress in the range up to $30 \%$ load ratio, therefore the shear resistance of the bondline had no influence on the fire resistance even for the thinnest studied cross section $(40 \times 200 \mathrm{~mm})$. Based on these investigations it can be assumed that also if the adhesive strength in the bondline is strongly influenced by the temperature (adhesive 1 respectively resultant 1, see Fig. 2b), in most common design applications failure will occur because of exceeding the bending resistance of the beam.

\section{FINGER JOINTS}

In order to investigate the influence of the adhesive strength in the finger joint of a structural timber element during fire the calculation model discussed in the above section was used. First, the temperature distribution of the whole cross-section for different times of fire exposure was calculated by a thermal finite element analysis. Then, the temperature distribution was implemented into CSTFire to calculate the normal stress distribution in the cross-section investigated. For the analysis the same cross-sections as given in previous paragraph were used. It was assumed that the beam consists of five lamellas with a thickness of $40 \mathrm{~mm}$. Further, the bottom lamella was assumed to be finger jointed at midspan of a simply supported and uniformly distributed loaded beam (Fig. 6) in order to obtain the greatest bending moment in the finger joint (worst case). By integration of the normal stresses over the residual cross-section of the bottom lamella the average tensile force in the bottom lamella was calculated (Fig. 6b) and compared with the temperature-dependent resistance of the finger joint.

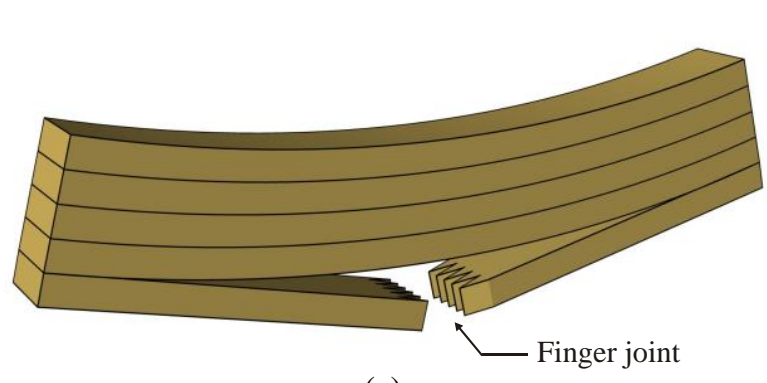

(a)

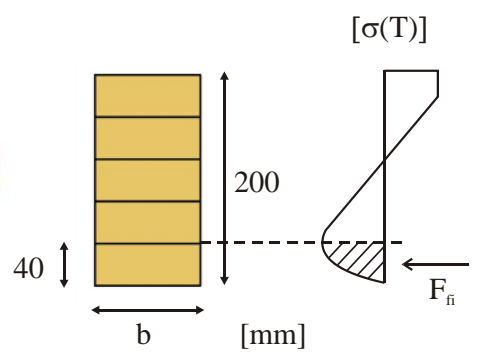

(b)

Fig. 6. (a) Glued laminated timber beam finger-jointed in the bottom lamella; (b) cross-section of the beam with normal stresses $\sigma(T)$ and corresponding tension force $F_{f i}$ in the bottom lamella in the fire situation.

In general, the following three different failure modes can be observed in finger joints:

1. Failure in the bondline caused by loss of cohesion of the adhesive,

2. Failure of the adhesion between adhesive and timber,

3. Failure of timber outside the bondline.

All failure types are influenced by the adhesive and wood strength. In order to investigate the influence of adhesive on the load-carrying behavior of the timber beams in fire the same temperature-dependent adhesive strengths as for the glued joints were used (Fig. $2 b$ ). The adhesive more sensitive to the influence of temperature represents the failure in the bondline caused by loss of cohesion in the finger joints. Further, the adhesive less sensitive to the influence of temperature represents failure outside the bondline. For the wood strength a bi-linear approach with a breakpoint at $100{ }^{\circ} \mathrm{C}$ and a relative strength of $75 \%$ of the strength at ambient temperature was assumed. In the case of adhesive 1 the load-carrying capacity of the timber beams is governed by the temperature-dependent strength of the adhesive at elevated temperature. For the timber beams bonded with adhesive 2 the load-carrying capacity is governed by the temperaturedependent strength of wood.

Figure 7 shows the calculated relative tensile resistance $R_{f i} / R_{20}$ of the bottom lamella with the finger joint for the investigated timber beams. It can be seen that for all timber beams the resistance is significantly reduced for adhesive 1 in comparison to adhesive 2 . Table 1 shows the influence of adhesive on the fire 
resistance assuming failure at a load ratio of $30 \%$ of the resistance at ambient temperature. The difference in fire resistance between adhesive 1 and 2 increases with increasing width of the timber beam. Depending on the geometries and load ratio it may be possible that after failure of the finger joint in the bottom lamella the timber beam will not fail. This aspect will be studied later with additional numerical analyses.
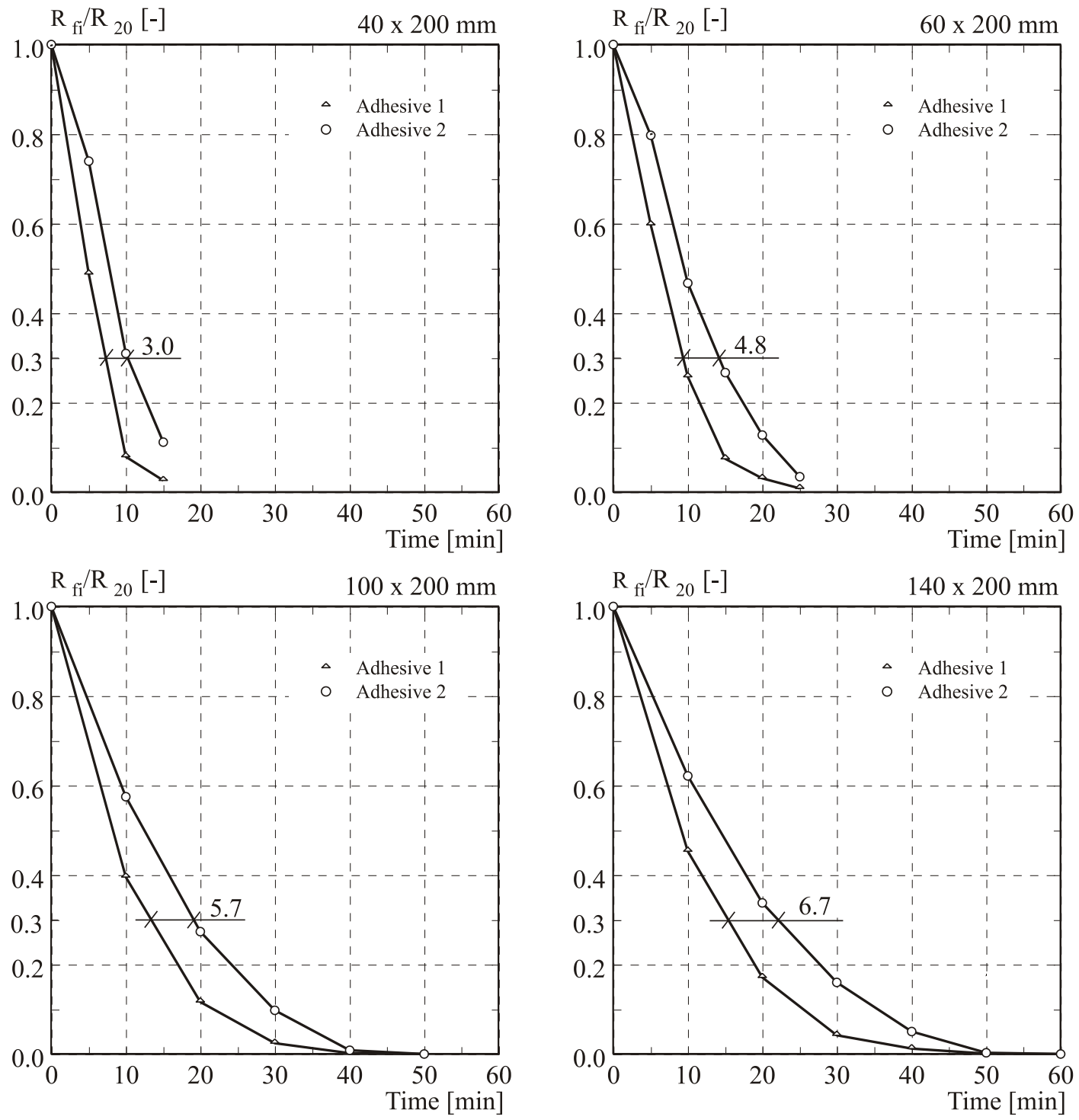

Fig. 7. Temperature-dependent reduction of bending resistance of glued laminated timber beams exposed to ISO-fire on 3 sides as a function of time for different cross-sections. 
Table 1. Fire resistance of glued laminated timber beams exposed to ISO-fire on 3 sides.

\begin{tabular}{|c|c|c|}
\hline $\begin{array}{c}\text { Beam dimensions } \\
(\mathbf{m m})\end{array}$ & $\begin{array}{c}\text { Fire resistance assuming failure } \\
\text { of adhesive 1 (min) }\end{array}$ & $\begin{array}{c}\text { Fire resistance assuming failure } \\
\text { of adhesive 2 }(\mathbf{m i n})\end{array}$ \\
\hline $40 \times 200$ & 6.5 & 9.5 \\
\hline $60 \times 200$ & 9.4 & 14.2 \\
\hline $100 \times 200$ & 13.5 & 19.2 \\
\hline $140 \times 200$ & 14.9 & 21.6 \\
\hline
\end{tabular}

\section{EXPERIMENTAL ANALYSIS}

A first series of tensile tests on specimens with finger joints pre-heated in an oven was performed within the framework of two project works at master level at ETH Zurich. The test specimens with a dimension of $800 \times 140 \times 40 \mathrm{~mm}$ were tested under tension at temperature of $20^{\circ} \mathrm{C}, 60^{\circ} \mathrm{C}, 100{ }^{\circ} \mathrm{C}$ and $140{ }^{\circ} \mathrm{C}$. For each adhesive and temperature studied, 10 specimens were stored in the oven and at the same time heated. The geometry of the specimens with a detail of the finger joint is shown in Fig. 8, right. The specimens were produced using visually graded lamellas made of spruce (Picea abies). The average density of the specimens was $(435 \pm 31) \mathrm{kg} / \mathrm{m}^{3}$ and the average moisture content was $(12 \pm 1) \%$. In order to obtain a reference value for the tensile strength, specimens without finger joints were tested in addition. The tensile tests were performed displacement-controlled with a velocity of about $0.02 \mathrm{~mm} / \mathrm{s}$ using a universal testing machine. The specimen was fixed to the machine by two clamping steel plates at each end of the specimen (Fig. 8b). The heating time varied between 1 and 2 hours. In order to monitor the temperature development constantly, the first and the last specimen of each series of tensile tests at elevated temperature was equipped with two thermocouples (one on the surface and one in the center of the specimen). Further, a reference specimen, equipped with eight thermocouples (four on the surface and four in the center of the specimen) was stored in the oven. As the reference specimen was permanently stored in the oven it completely dried. Thus, the temperature measured in the reference specimen was slightly higher than the temperature measured in the two additional specimens equipped with thermocouples. In order to assure that the specimens did not cool down during transferring and testing, the finger joint region of the specimen was wrapped into glass fibre insulation (Fig. 8b) and stored in the oven as well. The whole testing procedure starting with opening the door of the oven and concluding with the failure of the specimen under tension takes about 4-5 min. Preliminary tests showed that the temperature decrease of the specimen during the whole testing procedure was less than $5{ }^{\circ} \mathrm{C}$. No additional temperatures were measured while loading the specimens.

Four different one-component polyurethane adhesives (P1-P4) and one melamine-urea-formaldehyde adhesive (M1) were studied. All adhesives fulfill current approval criteria for use in load-bearing timber components according to EN 301 [18] and EN 15425 [19]. All finger jointed specimens were prepared by the same manufacturer of glued laminated timber beams under the strict supervision of the adhesives' manufacturer.

Table 2 summarizes the main statistical data (mean value $\overline{\mathrm{X}}$, standard deviation $s$ and coefficient of variation $v$ ) of all tensile tests including the reference tests performed without finger joints. The tensile strength measured at normal temperature $\left(20^{\circ} \mathrm{C}\right)$ agrees well with results found in literature $[1,2]$. For the finger joints glued with P1, P4 and M1 the tensile strength measured at normal temperature varied between 35 and $40 \mathrm{~N} / \mathrm{mm}^{2}$, i.e. between 83 and $93 \%$ of the tensile strength measured from the reference specimens without finger joints. For the finger joints glued with P2 and P3 the tensile strength was comparatively slightly lower (about $74 \%$ of the tensile strength measured from the specimens without finger joints) and showed the lowest coefficients of variation, indicative of an influence of the adhesives on the structural performance of the finger joints. 
Table 2. Main statistical data (mean value $\overline{\mathrm{X}}$, standard deviation s and coefficient of variation $\mathrm{v}$ ) of the tensile strength for all tensile tests performed.

\begin{tabular}{|c|c|c|c|c|c|c|c|c|}
\hline \multirow[t]{2}{*}{ Temp. } & \multirow{2}{*}{\multicolumn{2}{|c|}{ Tensile strength }} & \multirow[t]{2}{*}{ Ref. spec. } & \multicolumn{5}{|c|}{ Specimens glued with adhesive } \\
\hline & & & & P1 & $\mathbf{P 2}$ & $\mathbf{P 3}$ & P4 & M1 \\
\hline \multirow[t]{3}{*}{$20^{\circ} \mathrm{C}$} & $\overline{\bar{X}}$ & $\left(\mathrm{~N} / \mathrm{mm}^{2}\right)$ & 42.9 & 35.6 & 32.0 & 31.7 & 40.0 & 35.4 \\
\hline & $s$ & $\left(\mathrm{~N} / \mathrm{mm}^{2}\right)$ & 3.2 & 7.5 & 4.5 & 3.4 & 7.2 & 9.0 \\
\hline & $v$ & $(-)$ & 0.07 & 0.21 & 0.14 & 0.11 & 0.28 & 0.26 \\
\hline \multirow[t]{3}{*}{$60^{\circ} \mathrm{C}$} & $\overline{\mathrm{X}}$ & $\left(\mathrm{N} / \mathrm{mm}^{2}\right)$ & 35.4 & 25.1 & 26.3 & 25.5 & 33.8 & 35.1 \\
\hline & $s$ & $\left(\mathrm{~N} / \mathrm{mm}^{2}\right)$ & 4.3 & 5.0 & 2.6 & 4.0 & 3.7 & 6.8 \\
\hline & $v$ & $(-)$ & 0.12 & 0.20 & 0.10 & 0.16 & 0.11 & 0.19 \\
\hline \multirow{3}{*}{$100^{\circ} \mathrm{C}$} & $\overline{\mathrm{X}}$ & $\left(\mathrm{N} / \mathrm{mm}^{2}\right)$ & 31.2 & 17.5 & 16.2 & 18.1 & 25.1 & 30.2 \\
\hline & $s$ & $\left(\mathrm{~N} / \mathrm{mm}^{2}\right)$ & 10.7 & 3.0 & 4.6 & 3.4 & 3.8 & 4.9 \\
\hline & $v$ & $(-)$ & 0.34 & 0.17 & 0.28 & 0.19 & 0.15 & 0.16 \\
\hline \multirow[t]{3}{*}{$140^{\circ} \mathrm{C}$} & $\overline{\mathrm{X}}$ & $\left(\mathrm{N} / \mathrm{mm}^{2}\right)$ & 25.4 & 14.1 & 20.4 & 16.9 & 23.4 & 21.7 \\
\hline & $s$ & $\left(\mathrm{~N} / \mathrm{mm}^{2}\right)$ & 2.2 & 3.2 & 3.0 & 2.3 & 2.7 & 5.5 \\
\hline & $v$ & $(-)$ & 0.09 & 0.23 & 0.15 & 0.14 & 0.12 & 0.25 \\
\hline
\end{tabular}

The results showed substantial differences in temperature-dependent strength reduction and failure between the different adhesives tested. Figure 8a shows the comparison between the average tensile strength measured for the different adhesives as a function of temperature. Further, the results of the reference tests performed without finger joints (in Fig. 8a given as unjointed boards) and test results determined by Nielsen and Olesen [13] are reported. Following remarks can be made:

- As expected the reference specimens without finger joints show the highest tensile strength at normal temperature as well as at elevated temperature.

- The specimens glued with P1, P2 and P3 show a similar performance between 20 and $100{ }^{\circ} \mathrm{C}$, at $140{ }^{\circ} \mathrm{C}$, however, a recovery of strength was observed for the specimens $\mathrm{P} 2$. The specimens glued with M1 and P4 reached higher strength values than the specimens glued with P1, P2 and P3 within the whole temperature range tested. It is interesting to note the overall similar performance for the specimens glued with M1 and P4 and the good agreement with the test results determined by Nielsen and Olesen [13].

- At ambient temperature finger jointed specimens reached in average only about $85 \%$ of the tensile strength without finger joints. This can be attributed to the reduced net cross-section for finger jointed specimens, since in the finger joints usually there is a gap of about $0.5 \mathrm{~mm}$ at the finger-tips (see detail of finger joints in Fig. 8b).

The results of the first series of tensile tests on specimens with finger joints show that the load-carrying capacity of the finger joint is strongly influenced by the behavior of the adhesive used for bonding and thus confirm the results of the analysis. 


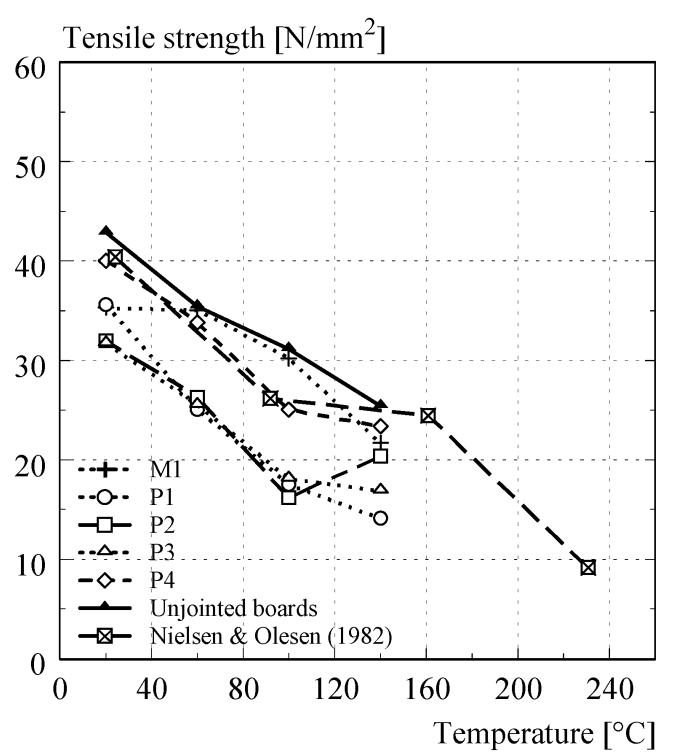

(a)

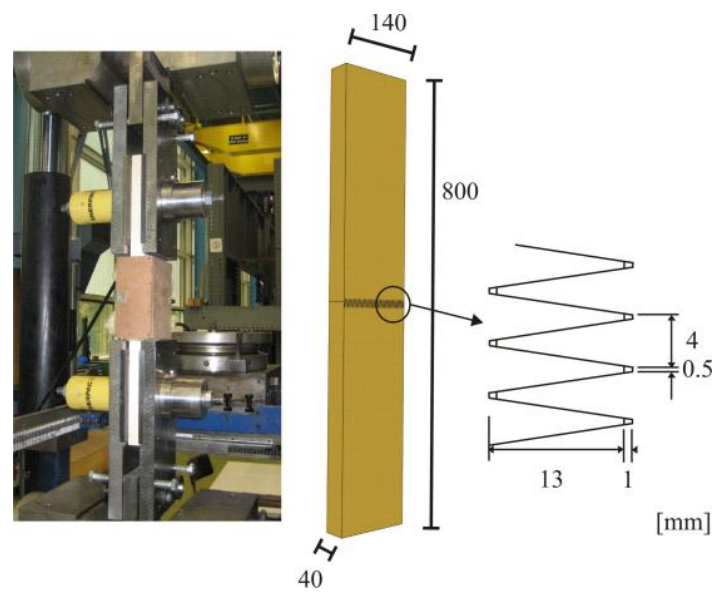

(b)

Fig. 8. Tensile strength as a function of temperature for all adhesives tested and for the reference tests performed without finger joints (in figure given as unjointed boards): (a) test results determined by Nielsen and Olesen [13]; (b) test set-up for the tensile tests and geometry of the test specimen with detail of the finger joint.

König et al. [15] conducted four-point bending tests on glued laminated timber beams exposed to ISO-fire on three sides. The glued laminated timber beams with dimensions of $135 \times 90 \mathrm{~mm}$ consisted of three lamellas and had a finger joint in the bottom lamella at midspan. At ambient temperature for 18 out of 20 tests failure was observed in the finger jointed bottom lamella of the beam. In the other two cases failure was caused by a knot. The fire tests were conducted with glued laminated timber beams finger jointed in the outer lamella on the fire-exposed tension side using different structural PRF, MUF and PUR adhesives. The results of the fire tests showed that the moment resistance of the beams with finger joints bonded with PUR and MUF adhesives was only between 70 and $80 \%$ of the moment resistance of beams with finger joints bonded with PRF adhesive and confirmed that the adhesive used in a finger joint can significantly influence the load-carrying capacity in fire.

The bending tests conducted by König et al. [15] were simulated with the calculation model presented in the previous paragraph. The temperature-dependent material properties for the wood tensile strength as well as for the wood and adhesive strength in the finger joint were calibrated to the results obtained with the tensile tests performed on specimens with finger joints pre-heated in an oven. Figure 9 shows the test results of the oven tensile tests and the temperature-dependent material properties assumed for the calculation model. The tri-linear model assumed for adhesive strength (with breakpoint at $60{ }^{\circ} \mathrm{C}$ and $100{ }^{\circ} \mathrm{C}$ ) represents adhesives that are strongly influenced by the temperature, whereas the bi-linear model of the wood strength in the finger joint simulates adhesives that are less influenced by the temperature (the wood strength is governing the load-carrying capacity of the finger joint).

Figure 10 shows a comparison between the results of the bending tests in fire [15] and the calculations performed. It can be seen that the presented model mainly overestimates the bending fire resistance; however, the results of the fire tests show a large scatter. In particular for adhesives with lower thermal stability (adhesive 1) the fire resistance of the beams has not been well predicted. 


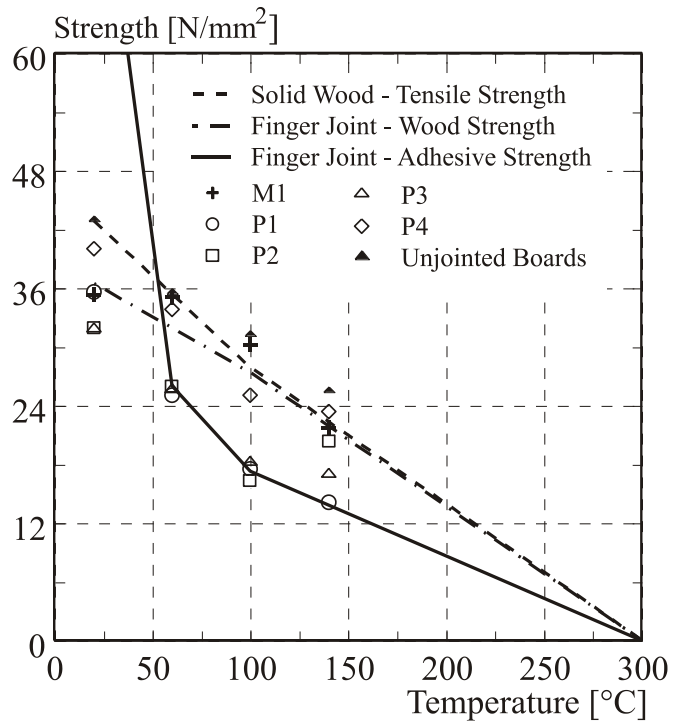

Fig. 9. Temperature-dependent material properties assumed for the simulation of the bending tests in fire [15] calibrated to results of tensile tests on specimens with finger joints pre-heated in an oven.

A possible reason is that temperature-dependent material properties assumed for the simulation are based on oven tests with specimens preheated at elevated temperature without loading. It is well known that oven tests tend to give higher strength values in comparison to fire tests due to the influence of loading [16,24]. Further, change in wood moisture and the fact that the states of moisture and temperature in the fire situation are transient and not stationary as usual in the oven tests play an important role. Thus, additional tensile tests on specimens with finger joint exposed to ISO-fire are planned in order to improve the correlation between the tensile oven tests at constant elevated temperature and fire tests. Once the strength reduction of finger joints in fire is known, its influence on the bending resistance of common glued laminated beams will be determined by performing Monte-Carlo simulations.

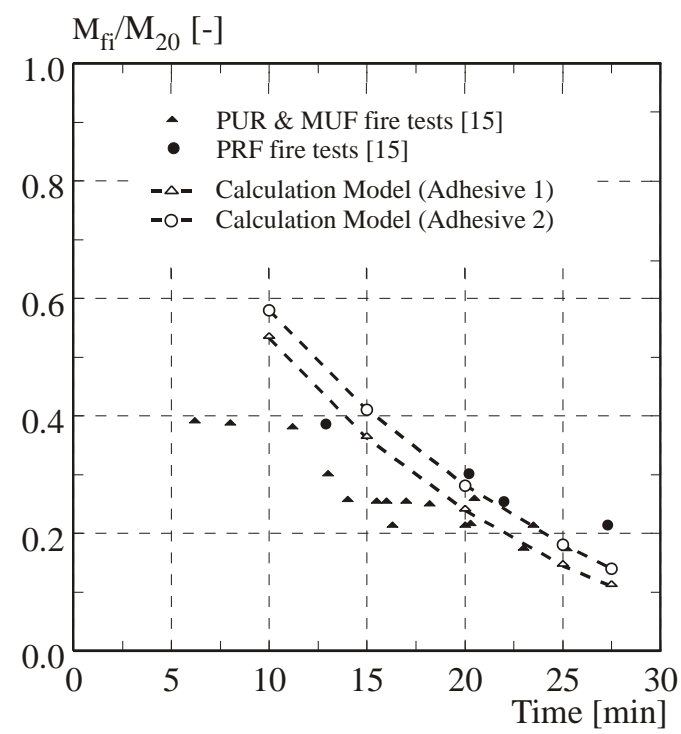

Fig. 10. Relative bending resistance as a function of time: comparison of test results for flexural loaded beams exposed to fire (tests performed by König et al. [15]) with results of calculations performed. 


\section{CONCLUSIONS}

The influence of the temperature-dependent material properties of the adhesive on the resistance of glued laminated timber beams exposed to fire was studied by means of a calculation model. The study shows that the behavior of adhesive at elevated temperatures used for the bondline between the lamellas has little influence on the resistance of the glued laminated timber beams in fire. Even if the adhesive in the bondline has low thermal stability, it is expected that the fire resistance will be governed by the bending resistance (and not by the shear resistance). On the other hand, the results of the analysis performed showed that the behavior of the adhesive at elevated temperature may influence the fire performance of the finger joints significantly.

A series of oven tensile tests on finger joints bonded with different adhesives were performed at elevated temperature. The results of the tensile tests showed a significant reduction in strength for the finger joints with increasing temperature. Further, substantial differences in strength reduction and failure were observed between the different adhesives tested. The results obtained by the oven tests were used for simulations of bending tests in fire on glulam beams with finger joints in the bottom lamella. As the comparison between the results of the calculations performed and results of fire tests is still not satisfactory, additional fire tests on beams and tensile tests on specimens with finger joint exposed to ISO-fire are planned in order to find a possible correlation between the tensile oven tests at constant elevated temperature and fire tests.

\section{REFERENCES}

[1] Larsen, H.J. (1980) Strength of Finger Joints, Paper CIB-W18/13-7-9, Proceedings of $13^{\text {th }}$ CIBW18 Meeting, Otaniemi, Finland.

[2] Heimeshoff, B., and Glos, P. (1980) Zugfestigkeit und Biege-E-Modul von Fichten-Brettlamellen, European Journal of Wood and Wood Products 38: 51-59, http://dx.doi.org/10.1007/BF02625304

[3] Ayarkwa, J., Hirashima, Y., Sasaki, Y., and Ando, K. (2000) Effect of glue type on flexural and tensile properties of finger-jointed tropical African hardwoods, Forest Product Journal 50(10): 5968.

[4] Serrano, E. (2000) Adhesive joints in timber engineering: Modelling and testing of fracture properties, Ph.D. thesis, Report TVSM-1012, Division of Structural Mechanics, Lund University, Sweden.

[5] Gonzàlez, G., Moya, R., Monge, F., Còrdoba, R., and Coto, J.C. (2004) Evaluating the strength of finger-jointed lumber of Gmelina Arborea in Costa Rica, New Forest 28: 319-323, http://dx.doi.org/10.1023/B:NEFO.0000040962.66091.db

[6] Vassiliou, V., Barboutis, I., and Karasterogiou, S. (2007) Effect of PVAc bonding on finger-joint strength of steamed and unsteamed beech wood (Fagus sylvatica), Journal of Applied Polymer Science 103: 1664-1669, http://dx.doi.org/10.1002/app.25079

[7] Özçifiçi, A., and Yapici, F. (2008) Structural performance of the finger-jointed strength of some wood species with different joint configurations, Construction and Building Materials 22: 15431550, http://dx.doi.org/10.1016/j.conbuildmat.2007.03.020

[8] Papadopoulos, A. (2008) The effect of acetylation on bending strength of finger jointed beech wood (Fagus sylvatica L.), European Journal of Wood and Wood Products 66: 309-310, http://dx.doi.org/10.1007/s00107-007-0223-3

[9] Dorn, H., and Egner, K. (1961) Brandversuche mit geleimten Holzbauteilen, Holz-Zentralblatt Stuttgart 87(28): 435-438.

[10] Dorn, H., and Egner, K. (1967) Brandversuche an Brettschichtverleimten Holzträger unter Biegebeanspruchung, European Journal of Wood and Wood Products 25(8): 308-320, http://dx.doi.org/10.1007/BF02615681 
[11] Dreyer, R. (1969) Brandverhalten von Holzträgern unter Biege- und Feuerbeanspruchung, Bauen mit Holz 71(5): 225-227.

[12] Nyman, H.J. (1980) The influence of temperature and moisture on the strength of wood and glue joints, Symposium on fire resistance of wood structures, VTT Symposium 9, VTT Technical Research Centre of Finland.

[13] Nielsen, P.C., and Olesen, F.B. (1982) Tensile strength of finger joints at elevated temperatures, Institute of Building Technology and Structural Engineering, Report No. 8205, Aalborg University, Denmark.

[14] Källander, B., and Lind, P. (2001) Strength properties of wood adhesives after exposure to fire, Nordtest Project no 1482-00, SP Report 2001:35, SP Swedish National Testing and Research Institute.

[15] König, J., Norén, J., and Sterley, M. (2008) Effect of adhesives on finger joint performance in fire, Paper CIB-W18/41-16-1, Proceedings of $41^{\text {st }}$ CIB-W18 Meeting, St. Andrews, Canada.

[16] Frangi, A., Fontana, M., and Mischler, A. (2004) Shear behaviour of bond lines in glued laminated timber beams at high temperatures, Wood Science and Technology 38: 119-126, http://dx.doi.org/10.1007/s00226-004-0223-y

[17] Clauss, S., Joscak, M., and Niemz, P. (2010) Thermal stability of glued wood joints measured by shear tests, European Journal of Wood and Wood Products, http://dx.doi.org/10.1007/s00107-010-0411-4

[18] EN 301 (2006) Adhesives - Phenolic and aminoplastic - For load-bearing timber structures Classification and performance requirements.

[19] EN 15425 (2008) Adhesives - One component polyurethane for load bearing timber structures Classification and performance requirements.

[20] ASTM D7247 - 07ae1 (2007) Standard Test Method for Evaluating the Shear Strength of Adhesive Bonds in Laminated Wood Products at Elevated Temperatures.

[21] Dassault Systemes Simulia: ABAQUS Online Documentation.Version 6.9, 2009.

[22] EN 1991-1-2 (Eurocode 1): Actions on Structures - Part 1-2: General Actions - Actions on Structures Exposed to Fire, CEN, Brüssel, 2002.

[23] EN 1995-1-2 (Eurocode 5): Design of timber structures, Part 1-2: General - Structural fire design, CEN, Brüssel, 2004

[24] König, J. Structural fire design according to Eurocode 5 - Design rules and their background. Fire and Materials 2005; 29:147-163, http://dx.doi.org/10.1002/fam.873

[25] König, J., and Walleij, L. One-dimensional charring of timber exposed to standard and parametric fires in initially unprotected and postprotection situation. Swedish Institute for Wood Technology, Trätek Report I 9908029, Stockholm, 1999.

[26] Schmid, J., and König, J. Fire exposed cross-laminated timber - modelling and tests. Proceedings of CIB W18, Meeting forty-three, Nelson, 2010. 